\title{
Vertientes del pensamiento crítico: tres revistas académicas sobre estudios del desarrollo
}

\author{
GEORGIA ARALÚ GONZÁLEZ PÉREZ*
}

En ocasiones suelo preguntarme por la vida oculta de específicas obras o publicaciones que llegan a mis manos. Me intriga pensar en las historias que se entretejen alrededor de ellas: su contexto, las personas involucradas, la finalidad de la información ahí vertida, los autores, los impresores, los lectores; sin embargo, siempre concluyo que es difícil, tal vez imposible, asirlo todo, develar cada capa, cada ínfimo acontecimiento.

Hoy, nos congregan tres revistas de la Unidad Académica de Estudios del Desarrollo de la Universidad Autónoma de Zacatecas. He de insistir que desde mi primer acercamiento hacia estas publicaciones tracé varias rutas para dilucidarlas. Metafóricamente, las asocié con un trébol en cuyo centro sobresale el concepto de desarrollo y junto a él la migración, la crítica y la observación. Históricamente, las identifiqué con una especie de engranaje que avanza y retrocede de modo intermitente, además las partes que lo conforman se vinculan para tratar de entender y analizar, desde diversas ópticas, fenómenos sociales no sólo dentro del contexto de América Latina sino también de Europa o Asia por ejemplo. Sociológicamente, antepuse al individuo inmerso en un sistema capitalista quien día a día se debate por alcanzar mejores condiciones de vida. Así, de manera paulatina fui accediendo a un entramado político, económico y social guiado por el acucioso estudio de autores interesados en el desarrollo de las sociedades.

En seguida, me remonté catorce años, para ser exactos a octubre de 2003, la revista Migración y Desarrollo surgía como un novedoso proyecto editorial de la Red Internacional de Migración y Desarrollo; el tópico la migración. De acuerdo con Raúl Delgado Wise se pretendía dejar el círculo vicioso y perverso de atraso, y en su lugar destacar «la emergencia (...) de un nuevo sujeto social extraterritorial que busca convertirse en agente del crecimiento de su lugar de origen». ${ }^{1}$ El objetivo, examinar múltiples realidades a fin de crear un trabajo académico interdisciplinario entre investigadores, organizaciones de migrantes, organismos no gubernamentales e instituciones públicas. Su estructura la constituyen tres secciones: Artículos inéditos, La voz de los actores y Coyuntura y debate. Aunque su diseño y presentación han ido evolucionando, mantiene su esencia e identidad. Hasta el momento se han difundido 27 números en el país y en el extranjero.

Continúo mi retroceso en el tiempo, ahora vuelvo seis años. En 2011, ante la crisis del sistema capitalista mundial y las apremiantes estrategias promovidas por los gobiernos caracterizadas por la destrucción, la sobreexplotación laboral, el autoritarismo, las incesantes

${ }^{1}$ Raúl Delgado Wise, «Presentación», Migración y Desarrollo, núm. 1, octubre 2003, p. 2. 
guerras, el horror en sí volcado hacia las colectividades, aparece la revista Estudios Críticos del Desarrollo. En palabras de Humberto Márquez Covarrubias,

es a partir de la epistemología del Sur o la epistemología de las alternativas que puede entreverse un claro, un mirador teórico privilegiado para vislumbrar la problemática concreta de los pueblos sumergidos en la explotación, la depredación y el exterminio. ${ }^{2}$

Por ello, la necesidad de dar apertura a espacios académicos que fomenten la crítica y el debate acerca de estos complejos temas. Los diez números editados hasta ahora incluyen artículos, debate y reseña.

Justo un año después del surgimiento de Estudios Críticos del Desarrollo se avista un proyecto más. En el primer trimestre del año 2012 comienza a circular una nueva revista: Observatorio del Desarrollo. Investigación, reflexión y análisis. El panorama social continúa siendo el mismo: inequidades, abusos, violencia, resquebrajamientos, despojos, pobreza, incertidumbre, sectores que convulsionan frente a las diversas realidades que les toca vivir. En medio de ese escenario y a fin de reavivar el pensamiento crítico, Observatorio del Desarrollo constituye un espacio de análisis y discusión respecto a las problemáticas capitalistas mundiales, cabe mencionar que entre los aportes más valiosos se encuentran las soluciones que se plantean cimentadas en posturas teórico-conceptuales críticas y propositivas. ${ }^{3}$ Frente a nosotros tenemos el número 15, un número polémico debido a la manera en que se abordan la educación y las universidades.

Luego de este breve recorrido permítaseme la siguiente analogía. En el ámbito regio-

\footnotetext{
${ }^{2}$ Humberto Márquez Covarrubias, «Editorial», Estudios Críticos del Desarrollo, vol. 1, núm. 1, 2011, p. 8.

${ }^{3}$ Ibid, p. 3.
}

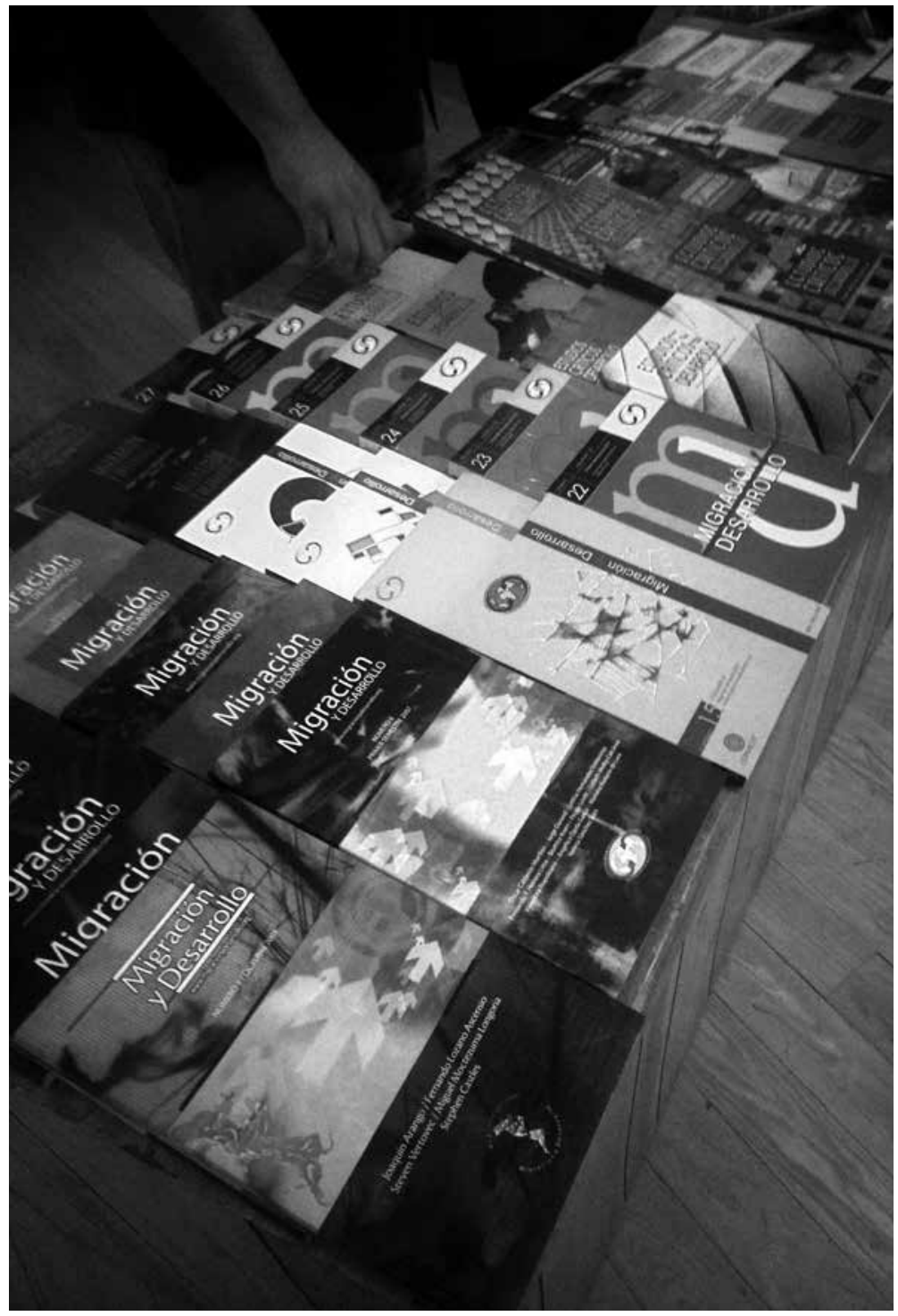

nal zacatecano e incluso nacional una de las revistas de mayor trascendencia es Dosfilos con 133 números publicados a lo largo de más de cuarenta años. En adición, su hermana menor, Corre, Conejo, registra ya 107 números divulgados en diferentes estados de la república mexicana. Con fundamento en lo anterior, Migración y Desarrollo cuenta con una trayectoria y reconocimiento que va en ascenso, además su parentela es mayor, Estudios Críticos del Desarrollo y Observatorio del Desarrollo enriquecen la visión del contexto El objetivo de las revistas es examinar múltiples realidades a fin de crear un trabajo académico interdisciplinario entre investigadores, organizaciones de migrantes, organismos no gubernamentales e instituciones públicas. reciente de las civilizaciones.

Soy consciente de que las revistas Dosfilos y Corre, Conejo son de carácter literario y las 
tres últimas académicas; pero, las unen dos aspectos esenciales: la rigurosidad en cada texto publicado y el minucioso, casi extenuante, cuidado de la edición. Por otra parte, es muy gratificante saber que investigadores de nuestra universidad, del país y el extranjero, preocupados por la situación actual latinoamericana y mundial se cuestionen, critiquen, debatan y construyan propuestas enfocadas hacia el mejoramiento de los pueblos. Ojalá que el ejercicio escritural manifiesto en las tres revistas se convirtiera en muchos de los casos en realidades, quizá de esa forma sería probable abatir la ignorancia, el autoritarismo de los gobiernos que asfixia, sofoca y aniquila mentalidades; quizá también se conseguiría dar solución a las crisis económicas y comenzar una verdadera transformación, quizá sólo entonces pueda hablarse de una emancipación real.

No deseo concluir sin resaltar que la presentación de estos tres números posee cierto simbolismo, pues marca el inicio del departamento de Ediciones de Estudios del Desarrollo.
A nombre de mis compañeros Selene, Erika, Israel y Aarón agradecemos a la Unidad Académica de Estudios del Desarrollo, en especial a Guadalupe Margarita González Hernández, a Raúl Delgado Wise y a nuestro director editorial, Humberto Márquez Covarrubias, por brindarnos la oportunidad de integrarnos a su equipo de trabajo y compartir con ellos esta maravillosa odisea.

Finalmente, desconozco los vaticinios del destino y más todavía tratándose de nuestra universidad; no obstante, tengo la confianza de que la integridad, la dedicación, la responsabilidad y el compromiso fortalecerán el trabajo de edición en la Universidad Autónoma de Zacatecas.

Texto leído durante la presentación de las revistas Estudios Críticos del Desarrollo, Migración y Desarrollo y Observatorio del Desarrollo editadas por la Unidad Académica de Estudios del Desarrollo el 11 de abril de 2017, en el marco del Festival Cultural

Zacatecas.

\section{Lectura recomendada}

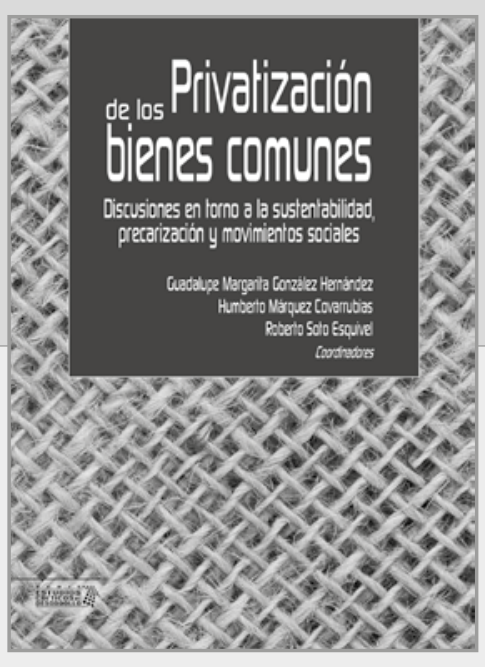

88

OBSERVATORIO DEL DESARROLLO • CIRCUNVALACIONES

Privatización de los bienes comunes. Discusiones en torno a la sustentabilidad, precarización y movimientos sociales

Guadalupe Margarita González Hernández | Humberto Márquez Covarrubias

| Roberto Soto Esquivel (coordinadores)

Miguel Ángel Porrúa / Universidad Autónoma de Zacatecas

Zacatecas, 2016

El presente libro está diseñado bajo dos temáticas de investigación. La primera referida al análisis de la globalización, crisis y alternativas al desarrollo, evidencia el actual proceso de transformación del sistema capitalista mundial a partir de una perspectiva histórica y contextualizada. La cuestión de desarrollo es caracterizada mediante los grandes problemas como el desarrollo desigual, el cambio climático y los conflictos sociales que se complementan con la exploración de las grandes alternativas de desarrollo en el plano teórico y práctico. La segunda estudia el desarrollo, la migración y los movimientos sociales en los ámbitos regionales y locales. Este libro es una segunda entrega de los trabajos realizados en el marco de la Red Internacional de Desarrollo, Sustentabilidad y Seguridad Humana, como una de sus tareas de discutir, intercambiar y difundir todo lo relacionado con el seguimiento del proceso de desarrollo, sustentabilidad y seguridad humana sin pretender establecer un paradigma único o definición exclusivamente normativa, en la búsqueda de una agenda alternativa que posibilite la participación estratégica de una amplia diversidad de sectores de la sociedad civil en el proceso de transformación social. 